\title{
Nursing Under the Old Poor Law in Midland and Eastern England 1780-1834
}

Abstract. This article uses data drawn from the overseers' accounts and supporting documentation in 36 parishes spread over four English counties, to answer two basic questions: First, what was the character, extent, structure, range of activities and remuneration of the nursing labor force under the Old Poor Law between the late eighteenth century and the implementation of the New Poor Law in the 1830s? Second, were there regional and intra-regional differences in the scale and nature of spending on nursing care for the sick poor, and if there were, how might we explain them? Keywords: Nursing; Old Poor Law; Professionalization; Nursing Income; Sickness and Poverty; Women and Nursing.

A flowering of the literature on the history of nursing has considerably strengthened our understanding of the origins, training, remuneration, career structure, and medical knowledge of nineteenth-century nurses. ${ }^{1}$ Studies of staff in voluntary hospitals ${ }^{2}$, military medicine ${ }^{3}$, and a renewed interest in workhouse infirmaries, have been significant drivers to the rewriting of nursing histories. Carol Helmstadter thus argues that doctors in nineteenth-century London teaching hospitals drove up standards as anaesthesia, increasingly complex surgery and changing concepts of patient care necessitated better nursing. ${ }^{4}$ Developing such ideas, Stuart Wildman's analysis of nineteenth-century censuses demonstrates that in the English midlands the average age of hospital nurses fell from 42 in 1851 to just 27 in 1901 at the same time as training levels improved and the recruitment network widened spatially. These trends reflect the fact that institutional reputation came to be associated with better and more professional patient management, rather than with radical improvement in 
therapeutics. ${ }^{5}$ Perry Williams adds colour to this picture, suggesting that standards improved when nurses came to be seen as pivotal to the moral and spiritual reform of the sick poor. ${ }^{6}$ The limited nursing capacity of the early voluntary hospitals ${ }^{7}$, was strongly addressed in London and prominent provincial cities such as Bristol and Birmingham ${ }^{8}$ such that the jack-of-all-trades image of institutional nurses was fading as recognisably 'modern' nursing gained traction in the $1840 \mathrm{~s}$ and $1850 \mathrm{~s} .{ }^{9}$ Even in the workhouses of the New Poor Law nursing was not invariably of poor quality, nor provided just by other pauper inmates. Certainly by the 1860 s, some poor law unions were funding the professionalization of staffing, and the burgeoning staffing files for nurses found by Steven King in mid- and later-nineteenth-century Bolton were not unusual. ${ }^{10}$

If our understanding of (particularly later) nineteenth century nursing has become increasingly sophisticated, the same cannot be said of nursing practice in the thousands of ecclesiastical parishes that comprised the Old Poor Law. This despite the fact that from the early eighteenth-century until its abolition in 1834 the Old Poor Law was by far the biggest non-familial provider/funder of nursing care in England and Wales. ${ }^{11}$ Jeremy Boulton's study of the parish of St Martins-in-the-Fields from the late seventeenth-century to the 1720 s, for instance, suggests that between $11-18 \%$ of total parish spending, as well as almost one third of all 'extraordinary' allowances, was absorbed by a small cohort of nurses most of whom provided care in de facto nursing homes. ${ }^{12}$ Such arrangements were short-lived - the foundation of the parish workhouse made nursing less lucrative and more transient ${ }^{13}$ - but the study provides a glimpse of the potential dynamism of nursing under the early Old Poor Law. Against the backdrop of the spiralling cost of poor relief from the 1780s (the so called "crisis" of the Old Poor Law), however, historians have generally had both little and little 
positive to say about poor law nursing. Samantha Williams's study of two small Bedfordshire parishes (Campton and Shefford) identifies 102 'carers' who were retained for broad nursing duties. Almost all were employed on an irregular basis and poorly paid, with the majority themselves becoming dependent upon poor relief at some point in their life-cycle. ${ }^{14}{ }^{15}$ Anne Borsay suggests that eighteenth and early nineteenth-century community nursing (including but not confined to poor law nursing) "was less abject than conventional wisdom alleges" but can draw on little empirical material relating to the Old Poor Law and ultimately concludes that it was institutional nursing that drove the professionalization process. ${ }^{16}$ Unsurprisingly, then, the image of the poorly paid, untrained, ineffectual and amateur (often pauper) nurse has become a leitmotif in relation to the medical care offered by the poor law.

This characterisation can be tested through the accumulation of individual micro-studies, but when these are set against marked differences in intra- and interregional support for the sick poor more generally ${ }^{17}$, the need for a wider frame of reference is clear. Was there any spatial patterning to spending on nurses and the role of nursing in overall care for the sick poor? Did all later eighteenth and early nineteenth-century communities have a large pool of ad hoc and poorly remunerated nursing labour as in Bedfordshire? How much were nurses paid in different areas? Can we find nursing homes developing in the provinces even as Boulton traces their decline in the Capital? Was the complexion of local nursing provision contingent (that is dependent mainly upon local conditions such as the rate-base, disease patterns, and the presence or absence of workhouses) or can we talk of longer-term 'customary' attitudes of parish officials towards nursing? How did competing demand impact the nursing labour market? ${ }^{18}$ And, did paupers come to expect nursing care as part of the parochial response to sickness? ${ }^{19}$ Answering questions such as these would help to 
draw back the chronological focus of recent revisionist work on nursing history and offer a more refined understanding of issues such as the role of the Old Poor Law as a care-giver, parochial responsiveness to demographic shocks, women's labour market position and remuneration, and communal sentiment towards the poor as welfare bills spiralled.

\section{DOING AND DEFINING}

To begin the task, this article analyses data (overseers' accounts, pauper letters, vouchers, vestry minutes, and overseer correspondence) drawn from 36 parishes in Berkshire, Norfolk, Northamptonshire and Wiltshire between the $1780 \mathrm{~s}$ and $1820 \mathrm{~s}^{20}$ Collectively, the four counties sit within the broad arc of southern, midland and eastern England where poor relief measured in money terms was at its most generous from the later eighteenth century. They provide coverage of the three major agrarian production regimes (arable, pastoral and mixed farming) and all lack the sorts of rapidly growing urban areas, at least until the end of the period covered here, that tend to skew understandings of the role and cost of welfare in other areas. At the same time, all four counties can boast a complex socio-economic patchwork running from the very smallest villages, through areas experiencing long-term industrial decline and to communities at the forefront of rapidly expanding workshop-based industries such as shoemaking and ribbon-weaving.

At the level of the individual county, we have selected groups of communities that are broadly comparable in terms of the presence and longevity of workhouses and the distribution of open and closed parishes. On the other hand, we have sought to include material from communities across the size distribution - the range for Wiltshire was between 55 and 4021, while that for Berkshire was between 253 and 
1995, for instance ${ }^{21}$ - topographical range and wealth spectrum appropriate to each county. The county sample as a whole is underweight in large urban areas (see appendix A), but the data provide an opportunity to explore the cost and character of nursing across a typological spectrum from the smallest hamlet to small market and industrial towns. To test the natural assumption in much poor law historiography that the level, form and distribution of welfare resources is intrinsically related to the wealth or socio-economic composition of individual communities we have conducted five separate analytical sweeps through different subsets of the intra- and inter-county data: the whole sample; comparing only communities with similar socio-economic and wealth complexion; topographical groupings; population bands; and communities segmented according to industrial or agrarian production regimes. Systematic differences of practice and experience emerging from these different configurations of the data are reported in the analysis that follows, though as a general observation the failure of socio-economic typology or wealth levels to offer predictive value in terms of the scale, duration and complexion of nursing provided is striking.

From the records relating to these parish samples it is possible to trace the proportion of all welfare spending that was dedicated to relief of the sick poor, and then more narrowly to focus on a comparative analysis of relative and absolute expenditure on nursing, the character of the nursing labour force (pay, careers etc.) and the attitude of parochial authorities to nursing within and between counties. While the data is not, and not meant to be, as rich as that deployed in individual microstudies, our analysis provides a wider frame of reference in which to inscribe future studies of this sort.

Initially, however, and in common with other authors, it is necessary to explore several key definitional and practical problems. Thus, a failure to engage with 
eighteenth and early nineteenth-century poor law nursing is at least partly explicable in terms of ambiguities over how to define what a nurse was. ${ }^{22}$ Can 'nursing' be distinguished from the medical attention provided by practitioners, both men and women, regular and irregular? Samantha Williams, following the early work of Margaret Versluysen, certainly thinks so, finding little curative as opposed to palliative care by nurses in Bedfordshire. ${ }^{23}$ Yet, the functional borderland between nurses and (regular or irregular) practitioner was by no means clear even in the census era. ${ }^{24}$ Eighteenth and early nineteenth-century doctors, midwives, wise people, and apothecaries frequently 'nursed' their patients in terms of sitting and watching, administering medicines, staying in the house of the sick person or even taking the sick into their own homes. ${ }^{25}$ In turn, it is sometimes difficult to make a distinction between provision of nursing services and membership of an occupational group of 'nurses' ${ }^{26}$ How often did a person have to provide nursing services to be regarded as a 'nurse', when we know that nursing in this period was provided across a spectrum of engagement, ranging from the full-time professional nurse who might in effect run a nursing home to those who provided ad hoc or single event nursing? If a parish turned regularly to a defined group of people, or if they maintained a notional register of people who might be called upon at need, we might justifiably call such people a reserve pool of nursing labour, to all intents and purposes 'nurses', even if they were not active at any given point. If, however, a parish turned to a nurse because they were physically closest to the sick person, because the sick person had asked for them, or because poor law officials required that nursing be provided as a condition of, supplement to or alternative for poor relief, the label 'nurse' might be inaccurate at best and actively misleading at worst. 
A second and related problem is how to reconstruct what nurses, however defined, actually did? Margaret Pelling argues persuasively that sixteenth-century plague and smallpox redefined the nature and content of nursing, necessitating more precise terminology to describe what nursing actually involved, and that fine distinctions between "keeping", "helping", and "watching", and "nursing", were created. $^{27}$ On the other hand, overseers' accounts for the eighteenth and early nineteenth centuries are replete with entries where the detailed composition of a bill for 'nursing widow $\mathrm{x}$ ' might comprise carrying, washing, mending, childcare, 'nursing', attending, 'doing for' someone, and laying-out the dead body all in one consolidated block. This suggests that officials maintained a very expansive definition of the duties associated with the label 'nurse'. ${ }^{28}$

Accepting this loose definition raises a third set of issues about the visibility (and hence countability) of different sorts of nurses and nursing services. The tasks of washing, mending and generally 'doing for' were most likely to be required, and would be most extensive and expensive, for those least tied into kinship and neighbourhood networks. Communities with transient populations would thus have the highest bills for nursing of this sort, while more representative (and less inclusive) nursing packages for those cemented more firmly into their communities would by definition be less visible. ${ }^{29}$ Similarly, nurses whose activities straddled parish boundaries would be less visible, while those providing nursing for chronic cases would tend to be more so. Equally, medical charities founded to work in conjunction with, or as a substitute for, poor law support were often small-scale and transient. Their records thus tend to be patchy but the effect of these organisations on the nature of local poor law provision and the sorts of duties undertaken by nurses might nonetheless be profound. ${ }^{30}$ 
This article treats the services of regular and irregular medical providers (even midwives unless they were paid extra for nursing) as separate from 'nursing care'. At the same time it makes a distinction in quantitative analysis between regular "nurses" and the providers of ad hoc "nursing services". We follow overseers themselves in adopting a wide and reflexive definition of 'nursing' in calculating expenditure levels, including services such as washing and laying-out as well as generalised bills related to "doing for" or the boarding of adults and children. There were in each county specialist institutions, such as voluntary hospitals, to which parishes subscribed and in which nursing would have been the greatest element of medical care. Subscriptions have not been ascribed as 'nursing' expenditure because of inconsistent information on which, if any, paupers benefited.

\section{QUANTITATIVE OVERVIEW}

The 36 parishes that lie at the empirical core of this article spent 14.5 per cent of their total welfare resources directly on 'medical relief', rising to 27.3 per cent where all cash payments to people on longer-term relief who were intermittently sick are counted as sickness relief. ${ }^{31}$ Irrespective of socio-economic typology or relative wealth levels, this proportion increased over the period of the so-called 'crisis' of the Old Poor Law from the 1780s to 1830s. Figure one traces the absolute amounts spent on nursing in our four counties, offering some important initial observations to frame this article.

[Figure One here] 
Together the parishes (collective population in 1801, 24,330) spent very considerably less on nursing annually than the single London parish of St Martin's, with its roughly similar population, earlier in the eighteenth-century. The distinctive role ascribed to nineteenth century London in the professionalization of nursing by historians clearly has much deeper roots than is usually allowed. There were, however, distinct differences between counties in amounts spent on nursing. For much of the period, Norfolk parishes were spending less than one quarter of their Berkshire counterparts on nursing, while in the later part of our period both Northamptonshire and Wiltshire parishes were spending at least double that of Norfolk parishes. Broad disparities persist even if we use the 1801, 1811 and 1821 population figures to obtain crude per capita spending measures. There was no systematic tendency for wealthier communities to spend more on medical relief and nursing in absolute terms or for areas with particular socio-economic complexions (arable versus pastoral or rural industrial versus rural) to spend more than others. Comparing just arable communities across the four county samples confirms the spending disparities reported in figure one and points to fundamental differences of practice and policy rather than simply differences in the complexion of the county samples or wealth levels.

The volatility in absolute spending levels, particularly outside Norfolk, is striking. In part this reflects the specific impact of epidemics ${ }^{32}$, and of the susceptibility of spending to the particular and often short-term needs of problematic individuals or families. Relatively few communities, even the most wealthy, paid for nursing services in every single year of the period, but the importance of nursing as a spending category could increase exponentially in some years. This is reflected in Figure two, which traces the peaks of spending on nursing at individual parish level. 
In Berkshire the town of Wallingford spent $59.5 \%$ of its medical relief on nursing in 1787, while in Northamptonshire the small rural parish of Whiston spent $46.6 \%$ in 1824. For Norfolk, the highest parish figure recorded in this sample was $51 \%$ for Scottow in 1783, while in Wiltshire, Sopworth spent $47 \%$ of its medical relief resources on nursing in 1811. Figure two provides tantalising evidence that absolute spending levels on nursing might have been rather higher earlier in the eighteenth century but the records are not of adequate quality to systematically explore this matter on the scale needed. Importantly, in most places and at most times the scale of nursing expenditure was not linked systematically to that on doctors, drugs, cash allowances etc. Nursing was, in other words, a discrete service, a point to which we return below.

[Figure Two here]

An analysis of the percentage of 'all relief' and 'all medical relief' spent on nursing, facilitates wider comparison. Both James Stephen Taylor (for Berkshire) and Samantha Williams (for Bedfordshire) have traced a limited place for nursing in the total poor law budget, and a relative decline in spending on nursing over time. Thomas suggests that the proportion of poor law resources devoted to nursing in seven Berkshire parishes fell from a slim $1.7 \%$ in the 1760 s to a tiny $0.006 \%$ by the early 1800s. Williams see a similar linear decline for Shefford (from a more healthy $4.8 \%$ in the $1790 \mathrm{~s}$ to $1 \%$ by the $1820 \mathrm{~s}$ ) and a slightly more varied trajectory for Campton (where the figure fell from $2 \%$ in the 1770 s to $0.6 \%$ in the 1780 s before rising and then falling to just $0.2 \%$ in the $1820 \mathrm{~s}$ ). ${ }^{33}$ In the 36 parishes analysed here, the picture is rather more complex. Only in the Berkshire parishes of Caversham 
$(1.44 \%)$ and Thatcham (3.85\%), the Wiltshire parish of Hardenhuish (1.04\%), and the Northamptonshire parish of Thorpe Achurch (1.34\%) did nursing absorb more than $1 \%$ of the total poor law budget for the period as a whole. At county-level, Berkshire devoted the highest percentage of its total welfare spending to nursing over the period $(0.95 \%)$, whilst Norfolk devoted the least $(0.22 \%)$. A systematic comparison of subsets of the parishes within and between counties reveals no tendency for wealthy or very poor parishes to devote higher or lower proportions of total spend to nursing. Equally there is no evidence of a systematic patterning to spending between communities of different socio-economic types and there is no trend at all for the proportion of total relief devoted to nursing to fall in the crisis of the Old Poor Law as Thomas and Williams suggest.

The use of total spending as a numerator is, however, problematic. Not all spending recorded in the year-end totals for 'poor relief' by overseers was on the poor. Account books frequently indicate spending heads such as contributions to the county-rate, legal disputes and interest on borrowed money. Moreover, it is imperative in interpreting these figures to allow for differential inflation. In most of the parishes analysed here, the costs of the different elements of medical relief broadly defined (drugs, midwives, average cash allowances for sickness etc.) saw modest inflation over the period, whereas the costs of rents, cash allowances for the underemployed, coals and other generic support increased significantly faster. In other words, differential inflation inevitably ate away at the share of medical relief (and, within this category, potentially nursing) in overall relief for the parishes and counties analysed.

Arguably, therefore, focusing on the proportion of parochial medical relief devoted to nursing affords a better understanding of attitudes towards nursing and 
nurses. The results of such an exercise (figures three to six) are striking. An unweighted whole-period average for Berkshire of $7.36 \%$ contrasts markedly with that for Norfolk of $3.44 \%$, (and to a lesser degree Northamptonshire and Wiltshire at 4.78 and 4.52 respectively), suggesting that the differences between the two counties in terms of absolute spending reflect very real underlying differences in attitudes and experiences. These county differentials are maintained even when we investigate parochial subsets devised to control for wealth and socio-economic typology. ${ }^{34}$

There were, however, strong intra-county variations in the importance of nursing as a spending category. A detailed consideration of trends for all 36 parishes suggests three models of parochial nursing culture. In Norfolk, for instance, we encounter parishes like Scottow (1801 population 406) or Bressingham (1801 population 545) the former with its sometimes substantial but always at least lowlevel spending on nursing and the latter with nursing the most common form of relief next to cash. In such places, nursing was clearly written into the very fabric of poor relief throughout the period. Other counties had their equivalent communities. In Wiltshire, for instance, both Sopworth and Hardenhuish spent more than $8 \%$ of their medical relief on nursing across the period. Trowbridge spent less (just over $2 \%$ per year) but it did so consistently across the period. In Northamptonshire the small rural parish of Thorpe Achurch consistently spent more than 9\%. While most parishes falling into this first typology were rural or rural-industrial in character, in none of the county samples do relative wealth or economic structure play a systematic predictive role. A second model is exemplified by the Norfolk parish of Thetford St Cuthbert (1801 population 1075) or the Berkshire parish of Caversham where spending on nursing was more substantial than elsewhere when it did occur but also considerably more intermittent. To these typologies, we might add a third, represented by the 
parishes of Salhouse in Norfolk (1801 population 375) or Wellingborough in Northamptonshire (1801 population 2093). In the former, nursing as a category of relief disappears altogether from 1809 , while in the latter such spending was at best patchy.

[Figures Three to Six here]

In short parochial commitment to nursing as a form of medical relief ranged on a spectrum between fragile and invulnerable in the last decades of the Old Poor Law. Higher absolute spending levels in Berkshire and lower levels in Norfolk in part reflected the distribution of the parochial sample across this spectrum. Crudely, Berkshire had more parishes with a consistent level of spending across the period than did Norfolk. This proximate explanation, however, merely points to a wider range of questions about the composition, scale and remuneration of the nursing labour force within and between counties, the nature of ingrained differences in official perceptions of what constituted medical relief, and perhaps to differential expectations on the part of the poor. It is to these issues that we now turn.

\section{THE SIZE AND COMPOSITION OF THE NURSING LABOUR MARKET}

The process of dissecting poor law accounts in order to trace the discrete number of nurses employed over the period considered here is hampered by frequent changes of marital status/name/alias and by the tendency for some overseers to intersperse their otherwise detailed record keeping with entries like "nursing for a stranger sick at Widow Hampton's". Such entries can be found periodically across the sample, often relating to nursing that was of very short duration or for sojourners. Table one 
consequently provides a minimum quantitative overview of the scale of the nursing labour force in the four counties. These numbers begin to contextualize the countylevel and intra-county differences in resourcing for nursing highlighted above.

\section{[Table One here]}

Norfolk parishes employed only around half the number of distinct nurses of their Berkshire counterparts, something that is unlikely to be explained by differential sickness rates and which is consistent across all of the typological subsets of the parochial data. At 1.6 discrete nurses employed per parish per year, the Berkshire figures are somewhat higher than Samantha Williams found for Campton (1.04) or Shefford (0.94) though the close fit of Norfolk to these Bedfordshire figures begins to suggest a wider 'eastern' model of poor law nursing.

As we might expect from the three nursing typologies outlined above, each of the counties demonstrated a range of parochial policies on a spectrum from the employment of many nursing staff to places where employment was much more irregular and short term. This patterning is not easily explained in terms of simple urban-rural or industrial-rural divisions. For Berkshire, it is certainly true that the town of Caversham employed the most nurses while the rural parish of Shellingford employed the least. Other urban communities like Thatcham, however, employed relatively few nurses, while rural parishes like Brimpton were a mere step away from the figures exhibited by Caversham. In Northamptonshire the relationship was even less distinct. The rural parish of Stoke Albany employed the fewest nurses (followed by the industrial town Wellingborough), while the proto-industrial parish of Woodford Halse provided the most. Other predictive variables may have more 
purchase. It is likely, for instance, that parishes occupied very different positions in the local and regional medical marketplace, with Stoke Albany employing few nurses because it was constrained by lack of supply in its very rural situation, something that might also apply to Thatcham. Differences in the scale of nursing between and within counties might also reflect strong variations in the range of nursing duties that communities would support, in turn a potential function of differences in underlying attitudes towards the sick and a subject to which we return below.

More detailed dissection of the evidence suggests that the bald figures of table one and figures three to six are underpinned by marked spatial differences in the composition of the nursing labour force. Some parishes were particularly likely to engage (relatively expensive) male nurses. Burghfield, in Berkshire (expending 5\% of medical relief on nursing) employed John Hudson, Ambrose Allen, Thomas Benham and William Garrard for nursing services between the 1760s and 1810s. Garrard in particular was a regular and well paid nurse who took patients into his home and was paid accordingly. ${ }^{35}$ Similarly, at Welton (Northamptonshire) the vestry appointed 11 male nurses between 1780 and 1824. By the early 1820s, Henry Ball was the main provider of nursing services in the parish and was paid significant sums for his work, including extras and gratuities in recognition of the standard of his nursing care. ${ }^{36} \mathrm{In}$ both places, employment of male nurses seems to have involved higher nursing bills than in comparable parishes within and between counties. Across the sample as a whole, however, employment of male nurses appears to have been more uncommon (less than 3\% of all nurses and carers) than Samantha Williams has suggested for Bedfordshire, where $15 \%$ of all nurses were men. Moreover, it is important to recognize that male nurses were disproportionately involved in the singular task of caring for the insane poor. In Caversham, Berkshire, for instance, three of the five 
male nurses employed over the period were engaged to deal with the insane John Bearfield. ${ }^{37}$ For some parishes, then, variations in the incidence of insanity and the propensity to employ male labour as a consequence begin to explain differences in the scale of spending on nursing. Moreover, the fact that insanity was essentially a random event at parochial level explains at least partly why we see so little association between levels of wealth and the scale of nursing expenditure.

This said, the vast majority of nurses across the sample and period were female and the vast majority of nursing tasks had little to do with insanity. ${ }^{38}$ Record linkage within the corpus of material used for this article allows us to say more about this female labour force and about some of the potential explanations for county-level and intra-county differences in emphasis on nursing. Figure seven traces the proportion of nursing events that can be ascribed to certain kinds of nurse. The categories employed are more numerous than those devised by Samantha Williams for Bedfordshire ${ }^{39}$, reflecting the more complex nursing structures and experiences that emerge when we consider multiple parishes across county boundaries. The numbers have several weaknesses, including the fact that the nursing typologies were not always discrete (see note to figure seven) and that record linkage is (even with family reconstitution data) overwhelmingly probabilistic and hence subject to error. At best, therefore, figure seven provides a broad overview. This notwithstanding, an initial reading of the data is that we must distinguish between professional or semiprofessional nurses within parishes, and those who made a living by providing nursing services across a wider ambit.

[Figure Seven here] 
As Samantha Williams has observed, almost no parishes were without a person taking up multiple nursing roles within any given year or time period. Figure seven suggests, however, that "professional" parish nurses in our sample were more common than in Bedfordshire, particularly for Berkshire and Northamptonshire. ${ }^{40}$ Such, for instance, was Mary White of Ardington, in Berkshire, who nursed 3-8 patients a year through 1790s and early 1800s, garnering almost two-fifths of all paid nursing assignments from the Ardington poor law in this period. Moreover, just as Berkshire appears to have had a larger cohort of professional nurses than other counties, so the range of their activities was also wider. Lucy Goodwin of Ardington provided regular midwifery services, medicines, boarding for sick parishioners and strangers and general nursing services to a substantial core of the sick poor in the parish. While she was never called a surgeoness, her activities suggest that she fulfilled the role. ${ }^{41}$ In the same parish, Dame Williams provided lodging for the sick, children in particular, and general nursing and caring services for the chronically sick and for those lodged by the parish with other families. Women such as these were occupied as nurses rather than simply providing nursing labour. While the relationship was not always consistent at parish-level, judged in the round counties and communities that witnessed greater reliance on professional nurses were also those devoting the larger proportions of medical relief to nursing. There was no systematic tendency for wealthier or urban parishes to employ more professional nurses than their poorer or rural counterparts.

In turn, we must distinguish the "professional" group from a smaller but nonetheless very important subset of nurses who travelled between parishes on nursing assignments. While this sort of activity has often been most closely associated with nursing of epidemic disease cases (especially smallpox, for which specialist 
nurses were paid a risk premium ${ }^{42}$, it is clear that officials were also willing to engage such nurses for other aspects of sickness too. In Berkshire, for instance, Mrs Mary Hatt was engaged by at least four of our parishes in the late 1820 s, while other Hatt women were to be found as midwives and nurses in almost all of the Berkshire parishes analysed, a de facto nursing dynasty. Overseers generally made a clear distinction between the role of these extra-parochial nurses and the more proximate nursing labour force. In 1805 at Burghfield (Berkshire) Elizabeth Money, a woman who had provided ad hoc nursing services in the past, was paid 5s. "for attending on Sarah Turner after the [professional] nurse was gone". ${ }^{43}$ For all of the counties analysed here there is clear evidence of the existence of a professional extra-parochial nursing network. Even in Norfolk, parishes such as Forncett St Peter routinely brought in nursing labour from outside. ${ }^{44}$ There was in turn a positive relationship at parish-level between a tendency to employ extra-parochial nursing (itself unrelated to wealth levels or socio-economic typology) and the absolute and proportionate spending on nursing, helping to explain some of the intra-regional differences highlighted thus far and suggesting that ingrained commitment to nursing could develop in some parishes and not others.

Professional nursing also overlaps with the "contingent nursing" categorisation of figure seven. In Northamptonshire, Wiltshire and Berkshire, bills issued by doctors provide a clear indication that they could engage their own nurses and charge the parish for out-of-pocket expenses in this regard, though in most parishes the identity of the nursing labour employed is subsumed within the general bill. We can be more precise about another aspect of contingent nursing: that in formal or informal institutional settings. On 29 September 1812, the vestry of Peterborough St. John took out a fire insurance policy (£150) for a "newly erected 
[and clearly substantial given the insurance amount] building used as a nursery and on a new building adjoining used as a place of confinement" at Westgate in the town. ${ }^{45}$ Other parishes converted existing buildings or carved nursing areas out of workhouse accommodation. The workhouse book of Bray (Berkshire), for instance, recorded on the 24 April 1792 that "the upper right hand front Garret be reserved as a sick room, into which all persons deemed ill by the Apothecary shall be removed, and a proper steady person appointed as a nurse."46

Contingent nursing was also provided by way of parishes buying service and space in the houses and establishments of parishioners. At its lowest-level this involved the boarding-out of individual sick paupers, but multiple boarding was surprisingly common. In Caversham, Mary Clisby was paid in the 1790s and 1800s for providing board and lodging for the sick in her own home, attending and taking in sick travellers and strangers, and for hiring out nurses who were clearly in her employ so that they could attend other cases on behalf of the parish. We can find similar examples in all of the counties analysed here, though the "nursing homes" were much more common in Berkshire than they were in either Northamptonshire and Wiltshire, and especially Norfolk, where such provision was rare. These places were not on the same scale as those found by Boulton in London, but communities that used or hosted such nursing homes - Caversham, Woodford Halse, Hardenhuish - tended to devote more of their overall and medical relief resources to nursing than parishes that did not. $^{47}$

Other forms of nursing exhibited less spatial diversity in terms of the regularity of parish spending. Ad hoc nursing care in response to sudden need was a commonplace. In all counties it was surprisingly common to find such care recorded in the overseers' accounts alongside that provided by more regular nurses for the 
same person. Hence, in Bray in January 1818 Mrs Hearn was paid 24s for nursing widow Haines, but Widow Brown was given an additional 3s. for "assisting the nurse". ${ }^{48}$ In terms of specialist nursing, most of our parishes paid for nursing related to maternity and postnatal care, albeit Berkshire parishes seem to have been more generous payers than those in other counties. Meanwhile, all parishes attached importance to nurses employed to deal with epidemic disease, especially smallpox, typhus and the diseases of childhood. Smallpox nurses were paid at a considerably higher rate (10-12s per week plus board and lodging even for nurses living within the parish appears normal) than those employed for regular nursing, and even more than inter-parish nurses of the sort that we encountered above. It thus follows that parochial susceptibility to smallpox and other infectious disease was a driver of the regularity and scale of expenditure on nursing and the share of nursing in overall and medical relief. This probably had a deflationary effect on the scale and a smoothing impact on the regularity of spending in urban areas where smallpox was endemic and the sick had access to more charities and institutions that provided nursing, obviating poor law responsibility. ${ }^{49}$

Clearly, then, some of the intra- and inter-county variations highlighted in figures one and three to six, relate directly to the nature and scale of the nursing labour force. Parishes employing significant numbers of external nurses, or where nursing-type homes were more common, as for instance in Berkshire, spent more (absolutely and proportionately) on nursing care than those which did not. There was also a relationship, though a complex one, between the size of the nursing labour force and the importance and scale of spending on nursing. It does not inevitably follow that those parishes employing most nursing labour would spend more (proportionately or absolutely) on nursing. Much depended on the duration and 
intensity of nursing seen as normal by officials and on unit pay costs (both issues examined in the next section). Much, however, also depended upon the constellation of nursing rather than simply its volume. In those parishes and counties (such as Berkshire or Northamptonshire) where multiple simultaneous and sequential nursing in a combination between specialist-ad hoc-professional-single-event was deployed for bouts of sickness, nursing expenditure tended to be higher absolutely and proportionately. This, we might imagine, is at least in part related to traditions of nursing under the Old Poor Law and perhaps to pauper expectations, an issue to which we return in the conclusion.

\section{NURSING IDENTITY, PAY AND PRACTICE}

The identity, careers, and pay of nurses are not always easy to reconstruct. Some nurses in the sample, especially those who provided ad hoc nursing services, were certainly paupers in receipt of an allowance at the time they started the nursing assignment. Indeed, this was one way in which officials could defray the unit costs of nursing, paying paupers less than others (via an addition to their allowance) or enforcing an expectation that nursing was a condition of relief. Jane Smith of Bray, a $2 \mathrm{~s}$ per week pensioner, was paid $3 \mathrm{~s}$ per week for nursing smallpox victims between May and July 1818 . The sum of $3 \mathrm{~s}$ per week was no doubt a considerable addition to her allowance, but it pales into insignificance when compared to what a specialist nurse would have expected. ${ }^{50} \mathrm{~A}$ few parishes (and generally not the poorest) came to rely heavily on this sort of labour in our period, dampening absolute and relative spending on nursing care. Yet, only a small proportion (22\%) of nurses employed on any basis were, at the point they started nursing, paupers. ${ }^{51}$ Indeed, the relationship between pauper status and nursing is complex. It is a striking feature of the sample, 
for instance, that many nurses subsequently became ill themselves. The act of nursing made those employed more vulnerable to dependence upon the poor law. Thus, in Ardington in 1799, William Church and his family were given cash payments totalling 18 1s 6d and Mary White (17s 6d) and (widow?) Wood (4s) were paid for nursing them. Immediately after this episode, the overseers recorded that "Mary White very ill" and paid Mary Purton (10s) and "Nurse Ballard" (12s) for nursing her. 'Dame' Ballard then fell sick in her turn and was nursed by a recovered Mary White (along with three others) in $1800 .{ }^{52}$ Unsurprisingly, then, while relatively few women were paupers at the time they nursed, a larger proportion (43\%) would subsequently become so.

Other nursing duties were probably undertaken by neighbours, lodgers, coresidents and kin, drawing upon a much older custom of nursing for all social groups. ${ }^{53}$ Without family reconstitution data it is difficult to specify the relationship between the sick and their nurses, even if they shared the same name. Moreover, it requires a close reading of the overseer's accounts (and potentially their linking with rate exemption and paying lists) to understand who was living with/lodged with whom. That kin and neighbours/co-residents were paid for nursing in all of our parishes is not in doubt; accounting entries such as "Elizabeth Harden for nursing her mother" make a clear connection. For some parishes a combination of vestry minutes and detailed accounts allows a more systematic perspective. In Welton, for instance, some $39 \%$ of all nursing engagements involved work by relatives, neighbours or coresidents. The employment of such labour was not, however, an avenue for costcutting. Such nurses were well-paid, and their services were often employed alongside other forms of medical relief and even alongside the services of other nurses. Here at least the attitude of officials towards nursing feels much more like a tradition than a 
reflexive balancing of immediate economy with the need to reduce long-term bills by ensuring that the sick returned to work and independence. ${ }^{54}$

Saying more about the identity of nursing labour in terms of marital status, age distribution, and supplementary occupations is hampered by lack of any wide-ranging census-type data. That widows were over-represented as nurses in most of the sample is clear. Working only from the standard notations in overseers' accounts ("Widow", "Dame" etc) suggests that more than one quarter of all nurses were widows, significantly greater than their likely presence in the background population in this period. ${ }^{55}$ For those parishes where vestry minutes and bastardy examinations survive it is also clear, as Samantha Williams has found for Bedfordshire and Pelling for Norwich, that the mothers of illegitimate children were well represented in the ad hoc nursing labour force. Internal evidence from the overseers' accounts also suggests this. At Hungerford, Berkshire, in May 1793, for instance, Bett Palmer was given 5s. "more than her pay [4s.] for nursing Widow Rosier", at the same time as she looked after her illegitimate child. ${ }^{56}$ It is impossible to establish whether other generalisations in the literature, particularly that nurses tended to be older women, also holds true for this sample, though pauper letters, overseer correspondence and settlement examinations do provide incidental evidence that this might be so. ${ }^{57}$

Our evidence of the duration of employment and the nature of pay for nursing is rather richer, and in any case is likely to explain more of the intra- and inter-county variations in the scale and importance of spending on nursing than the age or marital status of the labour force. Of course, reconstructing pay rates for nursing services (let alone income for individual nurses) is fraught with difficulty. Within and between parishes nurses were paid both by the week/month and by episode, and sometimes their pay was supplemented by board and lodging or other perquisites and sometimes 
not. Where such additions were usual, as for instance in Forncett St Peter in Norfolk, they were not consistently paid to the nurse as opposed to the sick person or the person lodging the nurse, so that the net income of nurses is difficult to discern in the overseers' accounts. This is made more complicated by the fact that nurses of whatever hue were not always paid in cash, but either requested or were assigned goods in kind, as for instance in Marlborough and Upavon in Wiltshire.

Naturally, rates of pay varied according to the duration of the nursing or the riskiness of the attendance. Rates varied too according to whether nurses were expected to look after individuals or families, and whether they were providing other aid than just nursing. In Caversham, for instance, one nurse was paid extra for giving up her bed to a sick patient. Payments were also unstable over the course of a year. In all of the counties and parishes analysed here, overseers made a distinction between ordinary nursing and that conducted during the harvest, for which extra pay was given. In August 1825 at Warham (Norfolk), Hannah Basham was given "extra in harvest time doing for the old people as usual 5s", while Widow Green was paid 7s. 6d. for providing nursing for her family and "Loss of time made no Gleaning", 58 Similarly, in Ardington, Berkshire, because John Emblin's wife was "ill in the harvest" in 1810 the overseer had to pay an over-the-odds 7s $6 \mathrm{~d}$ for nursing by Martha Alder. In 1823, the tables were reversed and John Lay's wife was ill in the harvest and required nursing, for which the overseers were required to pay Margaret Emblin an eye-watering $24 \mathrm{~s} 6 \mathrm{~d} .{ }^{59}$ Another subtle influence on the level of pay for nursing was whether an illness was expected to lead to a death, for which nurses were paid more than when a patient was expected to recover, even where additional labour was employed for laying out the body or sitting up with the deceased during their final hours. And, of course, we have already seen that paupers in receipt of relief and who 
provided nursing care could be, but were not inevitably, paid less than other nurses for their work.

Such observations are cautionary when trying to assess unit costs or cost ranges for different types of nursing. To them, and especially in light of the need to make intra- and inter-county comparisons, we might add the sometimes thin detail on how long a period payment to nurses actually covered, and the intensity of that nursing. It is certainly true, for instance, that overseers in the best-documented parishes factored payments according to the intensity of nursing. Thus, in Ardington, Berkshire in 1798 Nurse Ballard was given 1s. 6d. per week for two weeks for "looking after" John Clark but Mary Brown was given 13s. for providing nursing "Eleven weeks at several [times]" to the same person, clear recognition of a differing intensity of engagement on the part of the two nurses. Similarly, in 1801 Elizabeth [Nurse] Ballard and Lucy Goody shared a lump sum payment of 8s. 3d. for what must have been periodic low-level nursing of Taylor's wife, while in 1802 Goody was paid 10s. for two weeks of what must have been intensive nursing for Taylor in the run up to her death. Also in Ardington, the mother of Rachel Miles was paid 5 weeks at 6s per week for looking after her, and then 8 weeks at 3s, implying a different intensity of nursing recognised by the overseer, and perhaps even a de facto scale of nursing charges. ${ }^{60}$ Nor, perhaps, should we forget that some professional and semiprofessional nurses were actually paid even when they were not providing services. In Bray Mrs Lock was retained at 3s per week. ${ }^{61}$

Against this backdrop, tables two (which traces cost ranges for different types of nursing in the four counties analysed) and three (which traces the mean duration of different types of nursing in the same counties) drill more deeply into the character of 
the nursing labour market and the nature and causes of inter- and intra county variation in spending on nursing.

[Tables Two and Three here]

Berkshire parishes (on average and across all types of nursing) paid their nurses more than in the other counties. This disparity remains even where we group the parochial dataset across all four counties on the basis of wealth, broad topography or socio-economic typology. In particular, Berkshire parishes paid considerably more than their counterparts in Norfolk, the county which demonstrates the lowest absolute and proportionate expenditure on nursing, and even where we control for the size of the rate base in individual parishes. ${ }^{62}$ Moreover, and as table three suggests, there were also important inter-county differences in the duration of nursing. For Berkshire, the average duration across most nursing forms was higher than for the other counties. In turn, the juxtaposition of longer terms of general and chronic nursing with simultaneously longer periods of attendance, waiting and other more casual forms of nursing reflects the fact the Berkshire parishes were particularly likely to engage more than one nurse to provide care for an individual. The Berkshire parishes also demonstrated the longest periods of chronic nursing, while in Norfolk the juxtaposition of long-duration nursing care by relatives with the lowest figures for 'looking after' and chronic nursing probably points to a rather heavier reliance on cheaper family labour for long-term care than in the other counties. A sense that differences in spending on nursing within and (particularly) between counties might reflect ingrained cultural and policy attitudes towards the nursing of the sick poor, rather than simply the relative wealth of a community, thus begins to emerge. 
Moving from these observations to understand the sorts of livings made by nurses is hampered by occasional unspecified payments for 'nursing' and the fractured earning histories that we detect for inter-parish nursing. Nonetheless, for each of the parishes we can construct exemplary nursing careers and earning profiles. Such work demonstrates clearly that some nurses earned sums amounting to a significant proportion of the average male wage in the county concerned once we correct for the earning-effects of male underemployment. In the Berkshire parish of Brimpton, for instance, Nurse Coxhead was paid $£ 5$ ss. for nursing Thomas Hockley with the smallpox in August 1779, more than one quarter of the corrected average male wage in the area. This for a single nursing episode. In the same parish, Widow Fry was paid $31 \mathrm{~s} 6 \mathrm{~d}$ for nursing John Lee, plus $2 \mathrm{~s} 6 \mathrm{~d}$ for lending him her bed in 1788 , and she then made 41s. $6 \mathrm{~d}$ for nursing Luke Pembroke the next year for only 3 weeks work. In 1812, Mrs Pool was paid $£ 11$ 2s. to board, lodge and nurse John Lawrence for six months, fully two thirds of the corrected annual average male wage for the area at this date. ${ }^{63}$ In Caversham Mary Wilder was generally nursing 2-3 people at a time and getting between $6 \mathrm{~d}$ and $3 \mathrm{~s} 6 \mathrm{~d}$ per week per person in the later eighteenth and early nineteenth-centuries. ${ }^{64}$ These are not equivalent to the sorts of sums traced by Boulton in London, but they are nonetheless significant.

Figures for parishes in other counties may well have looked even more remarkable to ratepayers. In Welton, for instance, Widow Heath was paid an average of $£ 13$ per year for various nursing services between 1788 and 1802, fully three-fifths of the corrected average male wage for the area. Even in the evidently more parsimonious Norfolk parishes Mary Dixon earned an average of $£ 8$ 6d per year between 1794 and 1808 for nursing provided to the parishioners of Forncett St Peter. These incomes are within or exceed the range of $£ 5-£ 10$ per annum that Perry 
Williams sees as normal for nurses (not just poor law nurses) in this period. ${ }^{65}$ In common with the work of Samantha Williams on Bedfordshire, only a small minority of all nurses ( $12 \%$ across the sample as a whole) earned sums that would have made a fundamental contribution to the household economy. This said, there was a significant difference between the experiences of nurses in Berkshire and to a lesser extent Northamptonshire, and those in Norfolk and Wiltshire. In the former counties, a significant minority of all nurses (27\%) gained consistent employment and income from their roles, reflecting a policy of attaching nursing to most cases of sickness and maternity and a local labour force in which nursing was often a discrete occupation rather than an addendum to a range of other work. The opposite was true of Norfolk and to a lesser extent Wiltshire, where nursing tended towards the cheaper end of provision and duration, as tables two and three show. Across the whole sample some $37 \%$ of nurses made between $£ 1-4$ per year, providing services on a sufficiently regular basis for them to have regarded such sums as part of their family economy and for us to regard them as "nursing labour". In short a deeply inscribed model of poor law nursing which concentrates on casual provision, often by other paupers, has a limited basis in reality, particularly for counties like Berkshire.

\section{CONCLUSION}

The empirical basis on which to understand nursing under the Old Poor Law has, until now, been relatively slim. This despite the fact that parochial authorities spent tens of hundreds of thousands of pounds annually on nursing care widely defined. Even in the midst of the so-called "crisis" of the Old Poor law most parishes in most counties continued to see nursing as an integral part of sickness relief, something to be provided as a discrete service separate from consideration of the need for doctors, 
drugs and cash allowances. Historiographical views of the nature and quality of this nursing - essentially characterising it as casual, residual, poor quality and often undertaken by paupers, in contrast to the professionalised service we see emerging from the $1840 \mathrm{~s}$ - are deeply entrenched. The material analysed here questions this view; in counties like Berkshire parishes had access to a substantial core of "professional" nurses drawn from a local and intra-regional pool of nursing labour. These men and women were often well paid, undertook nursing intensively and sometimes founded their own nursing homes. ${ }^{66}$ Such labour was neither casual nor residual. Nor was it cheap.

Yet there were also notable differences between parishes in each county and, even more markedly, between counties in the level of absolute spending on nursing, the $\%$ of medical relief devoted to this task and in the intensity and nature of nursing undertaken. Only by assembling considerable datasets and analysing them on a comparative basis do such variations come to light. These differences were remarkably stable over time and, contrary to many of the implicit assumptions written into the historiography of the poor law, showed little systematic relationship to either the relative wealth or parishes/counties or the their socio-economic composition. We have suggested a three strand model for characterising the experiences of individual communities, running on a spectrum from nursing that was deeply ingrained into the basic policy making of parishes through to places where commitment to nursing as part of relief and medical relief was fragile and inconsistent. This model can help to locate further micro-studies of nursing practice at parochial level for the Old Poor Law period. It also highlights some very important spatial patterning, notably a disparity between a broadly defined 'eastern' experience (relatively low expenditure and low intensity nursing) represented by Norfolk and Bedfordshire and a 
central/southern policy (relatively high expenditure with a strong core of professional nurses) seen most keenly in Berkshire but also Wiltshire and Northamptonshire.

Constructing an explanatory model for inter- and intra-county variations in attitudes towards nursing is problematic. Different confluences of circumstances could lead to the same outcomes in terms of spending on nursing. For instance, parishes firmly cemented into the regional medical market and those isolated from it might end up spending relatively little on nursing, the one because officials had plenty of choice and could keep down costs, and the other because there was simply not the wide range of nursing choices that might otherwise underpin more substantial costs. Nonetheless, it is clear that a heavy susceptibility to epidemic disease could drive higher nursing expenditure than in other places; that the formation of nursing homes was positively related to spending; and that the more frequently parochial officials drew on a core of professional nursing labour the higher the $\%$ of their local welfare resources spent on this task. These proximate variables do not, however, provide a complete picture, nor adequately explain the broad inter-county differences in attitudes towards nursing outlined in this article. For more clarity we must turn to a sense that for some parishes and county communities providing nursing as part of a response to medical need amongst the poor was a basic tenet of policy. This was certainly the case in Berkshire, in a way that is simply was not in Norfolk. In the latter county nursing tended to be provided at the less intensive, less professional and less expensive end of the potential spectrum. Norfolk communities did not lack the money or the nursing networks to adopt a different approach; they lacked the history of action and the will to change.

In turn, we see these different county attitudes reflected in and shaped by the demands for nursing made by paupers in the letters they wrote back to their parishes 
of settlement when they became sick and were 'out of their place'. Paupers brought up or living in Berkshire, Wiltshire and Northamptonshire inscribed an expectation that they would receive support for nursing into the basic rhetoric of their narratives. They asked, often unsubtly, how much they were to receive towards nursing care or who was to be nursing them. Nursing care, in other words, was to be understood as part of the necessary infrastructure (alongside food and money) in the appropriate parochial response to illness amongst the deserving poor. ${ }^{67}$ Equivalent writers from Norfolk asked whether they would be given help with nursing. The rhetorical and strategic differences embodied in the two types of letter are slim but nonetheless crucial. They point to a shared set of expectations in both counties, expectations which we in turn see played out in the money spent on nursing and the propensity to turn to professional nursing networks. ${ }^{68}$

Funding: None

${ }^{1}$ For early work: Brian Abel-Smith, A History of the Nursing Profession (Oxford: Oxford University Press, 1960); Ruth G. Hodgkinson, The Origins of the National Health Service: The Medical Services of the New Poor Law 1834-71 (London: Croom Helm, 1967); Robert Dingwall, Anne-Marie Rafferty and Charles Webster, An Introduction to the Social History of Nursing (London: Routledge, 1988).

${ }^{2}$ Chris Maggs, "Nurse recruitment to four provincial hospitals 1881-9121," in Celia Davies, ed., Rewriting Nursing History (London: Croom Helm, 1980), pp.1-40; Keir Waddington, "The nursing dispute at Guy's hospital 1879-1880," Social History of Medicine, 1995, 8, 211-30; Keir Waddington, Charity and the London Hospitals, 1850-1989 (Woodbridge: Boydell, 2000). 
${ }^{3}$ Anne Summers, Angels and Citizens: British Women as Military Nurses 1854-1914 (London: Routledge and Kegan Paul, 1988); Eric Gruber von Arni, Hospital Care and the British Standing Army 1660-1714 (Aldershot: Ashgate, 2006), pp.69-116 passim; Matthew Kaufman, Surgeons at War (London: Greenwood, 2001).

${ }^{4}$ Carol. Helmstadter, "Robert Bentley Todd, Saint John's House, and the origins of the modern trained nurse," Bulletin of the History of Medicine, 1993, 67, 282-319; Carol Helmstadter, "The passing of the night watch: Night nursing reform in the London teaching hospitals, 1856-90," Canadian Bulletin of Medical History, 1994, 11: 23-69; Carol Helmstadter, "Early nursing reform in nineteenth-century London: A doctor-driven phenomenon," Medical History, 2002, 46: 325-50; and Carol Helmstadter and Judith Godden, Nursing Before Nightingale, 1815-1899 (Farnham: Ashgate, 2011), pp. 1-24. Sue Hawkins, Nursing and Women's Labour in the Nineteenth-Century: The Quest for Independence (London: Routledge, 2010) uses the example of St George's Hospital, London, to suggest how this increasing professionalization fed through into wider considerations of career development for women.

${ }^{5}$ Stuart Wildman, "Changes in hospital nursing in the west Midlands 1841-1901," in Jonathan Reinarz, ed., Medicine and Society in the Midlands 1750-1950 (Birmingham: Maney Publishing, 2007), pp.98 and 104.

${ }^{6}$ Perry Williams, "Religion, respectability and the origins of the modern nurse," in Roger French and Andrew Wear, eds, British Medicine in an Age of Reform (London: Routledge, 1991), pp.234-7.

7 Susan.Lawrence, Charitable Knowledge: Hospital Pupils and Practitioners in Eighteenth Century London (Cambridge: Cambridge University Press, 1996); 
Bronwyn Croxson, “The foundation and evolution of the Middlesex Hospital's Lyingin service, 1745-86," Social History of Medicine, 2001, 14, 27-57.

8 Mary Fissell, Patients, Power and the Poor in Eighteenth Century Bristol (Cambridge: Cambridge University Press, 1991); J. Reinarz, The Birth of the Provincial Hospital: The Early Years of the General Hospital, Birmingham 17651790 (Stratford: Dugdale Society, 2003).

${ }^{9}$ For a review of this process, see Anne Borsay and Billie Hunter, "Nursing and midwifery: Historical approaches," in Anne Borsay and Billie Hunter, eds, Nursing and Midwifery in Britain since 1700 (Basingstoke: Palgrave, 2012), pp. 8-9 and Anne Borsay, "Nursing, 1700-1830: Families, Communities, Institutions," in Borsay and Hunter, Nursing and Midwifery, p.24. Also Martha Vicinus, Independent Women: Work and Community for Single Women 1850-1920 (London: Virago, 1985) and Chris Maggs, ed., Nursing History: The State of the Art (London: Croom Helm, 1987).

${ }^{10}$ Steven King, Women, Welfare and Local Politics 1880-1920: "We Might be Trusted" (Brighton: Sussex Academic Press, 2005). For a rather more negative perspective which characterises New Poor Law infirmaries as in a "desperate state" see Christine Hallett, "Nursing, 1830-1920: Forging a profession," in Borsay and Hunter, Nursing and Midwifery, p.55. Wildman, “Changes”, p.106, suggests that even in the 1890s poor law institutions recruited nurses from a more local pool than other institutions.

${ }^{11}$ The literature on care of the sick poor and nursing is rather richer for the sixteenth and seventeenth centuries than for the subsequent 130 years. See Andrew Wear, "Caring for the sick poor in St. Batholomew's Exchange, 1580-1676,", in William Bynum and Roy Porter, eds, Living and Dying in London (London: Wellcome Trust, 1991), pp.41-60; Marjorie McIntosh, "Networks of care in Elizabeth an English 
towns: The example of Hadleigh, Suffolk,", in Peregrine Horden and Richard Smith, eds, The Locus of Care: Families, Communities, Institutions, and the Provision of Welfare since Antiquity (London: Routledge, 1998), pp.71-89.

12 Jeremy Boulton, "Welfare systems and the parish nurse in early modern London, 1650-1725," Family and Community History, 2007, 10, 127-52. On the provinces, see Fissell, Patients, Power, pp.67-9.

${ }^{13}$ Boulton, "Welfare systems".

${ }^{14}$ See Abel-Smith, A History.

${ }^{15}$ Boulton, "Welfare systems"; Samantha Williams, "Caring for the sick poor: Poor law nurses in Bedfordshire c.1770-1834," in Penelope Lane, Neil Raven and Keith Snell, eds, Women, Work and Wages in England 1600-1850 (Woodbridge: Boydell, 2004), pp.141-69.

${ }^{16}$ Borsay, "Nursing, 1700-1830", pp. 27-29 and 37-39. Quote at p.29. Christine Hallett does not mention the Old Poor Law. See Hallett, "Nursing, 1830-1920".

${ }^{17}$ The term 'sick poor' is, as Fissell, Patients, Power, p.3, points out, a shorthand. Not all the sick poor came into contact with the poor law and even those who did were also likely to have other sickness episodes dealt with via self-dosing or care-in-the community.

18 Post-1800, demand from the poor law for nurses was supplemented by demand from lying-in charities and sickness relief societies that sprang up in many communities, with consequences for wage levels. Sylvia Seligman, "The Royal Maternity Charity," Medical History, 1980, 24, 403-18 and Croxson, "The foundation", pp.44-48. Croxson's discussion of the scale of hospital births and the rise of competing charities to enable women to give birth in their own homes implies 
nursing care on a considerable scale even in the eighteenth-century. For Bristol, see Fissell, Patients, Power, pp.118-19.

${ }^{19}$ Margaret Pelling, The Common Lot: Sickness, Medical Occupations and the Urban Poor in Early Modern England (London: Longman, 1998), pp.200-01 shows that in the sixteenth-century, poor families expected to be able to call outside help at times of sickness, even if only for washing.

${ }^{20}$ This is by far the largest parochial sample ever established and represents places with complete runs of overseer data for the period. In addition, the article uses detailed examples from other parishes where data is rich but fractured.

${ }^{21}$ In 1801, the collective parish population sizes were 5282 in Berkshire, 6641 in Northamptonshire, 4446 in Norfolk and 7958 in Wiltshire.

${ }^{22}$ Pelling, Common Lot, pp.172-3; Sara Mendelson and Patricia Crawford, Women in Early Modern England (Oxford: Oxford University Press, 1998), pp.284-8 and 33741. Also Borsay and Hunter, "Nursing and midwifery", p.3.

${ }^{23}$ Williams, "Caring", pp.145.

${ }^{24}$ Owen Davies, "Female healers in nineteenth-century England," in Nigel Goose, ed., Women's Work in Industrial England: Regional and Local Perspectives (Watford: Hertfordshire University Press, 2006), pp.228-49. See also Borsay, "Nursing, 17001830 ", p.24, who argues that nursing and doctoring had been entwined since the early modern era.

25 See, for instance, Matthew Beardsley and Neil Bennett, eds, "Gratefull to Providence": The Diary and Accounts of Matthew Flinders, Surgeon, Apothecary and Man-Midwife 1775-1802 (Woodbridge: Boydell, 2007); Fissell, Patients, Power, p.65. 
${ }^{26}$ Not least because, unlike other European countries, religious organizations played relatively little part in providing nursing care for the poor in eighteenth- and early nineteenth-century England. See Colin Jones, The Charitable Imperative: Hospitals and Nursing in Ancien Regime and Revolutionary France (London: Routledge, 1989); Susan Dinan, Women and Poor Relief in Seventeenth-Century France: The Early History of the Daughters of Charity (Aldershot: Ashgate, 2006). Wildman, "Change", p.99, suggests that there were 26 religious groups offering nursing care by 1864 , though there was a distinct London focus to their activities.

${ }^{27}$ Pelling, Common Lot: Sickness, pp.179-201, pp.186, 194-95.

${ }^{28}$ For Williams, "Caring", p.149, generalised entries encapsulated by the phrase 'doing for' comprise the 'vast majority' of care work. In the sample used here this is not the case, with 'nursing' as a phrase and expenditure item appearing much more commonly and deliberately.

${ }^{29}$ For a discussion of this point see Fissell, Patients, Power, p.101.

${ }^{30}$ Anne Summers, "The cost and benefits of caring: Nursing charities c.1830-1860," in Jonathan Barry and Colin Jones, eds, Medicine and Charity Before the Welfare State (London: Routledge, 1991).

${ }^{31}$ The category 'medical relief' is contingent. Williams, "Caring”, pp.141-4 includes food, allowances, direct medical relief and subscriptions to hospitals. Eric Thomas, "The treatment of poverty in Berkshire, Essex and Oxfordshire 1723-1824", (Unpublished PhD, University of London, 1971), p.65, calls for a more expansive definition. In this sample almost two-thirds of all spending would become "medical relief' if we were to follow the emerging historiography of the aged poor, which has come to link their relief to progressive disability and inability to labour. For the current study medical relief is defined to include nursing, doctoring costs, drugs, cash 
allowances, food and fuel, rent, funerals and short-term allowances to the relatives of deceased paupers. The costs of building dedicated medical facilities in specific parishes are excluded.

32 Though Eric Thomas, "The Old Poor Law and medicine”, Medical History, 1980, 24, 1-19, pp.10, argues that the poor were generally inoculated en mass and hence better protected from smallpox at least than the general population.

33 Stephen Taylor, "Aspects of the socio-demographic history of seven Berkshire parishes in the eighteenth century" (Unpublished PhD, University of Reading, 1987), pp.397; Williams, "Caring”, p.165.

${ }^{34}$ These differences persist even where we compare similar communities across the county samples. Interestingly, wealthier Norfolk communities spent less as a \% of medical relief on nursing than their exact counterparts in Berkshire.

${ }^{35}$ BRO DP29/12/1-5, Overseers' accounts.

${ }^{36}$ NRO 356p/16-24, Overseers' accounts.

${ }^{37}$ BRO DP182/12/11, Overseers' accounts.

${ }^{38}$ Williams, "Religion, respectability," p.240. Davies, "Female healers," p.229 also implicitly assumes all nurses were female.

${ }^{39}$ Williams, "Caring”, p.152 talks of 3 types of carer. Also Fissell, Patients, Power, pp. 60,67 , and 102 .

${ }^{40}$ Williams, "Caring", p.158. Focussing on training and status rather than simply on the intensity of their work, Borsay and Hunter, "Nursing and Midwifery", p.21, suggest that "professionalization" was a product of the later nineteenth-century. Since "professional" is a perceived as well as an ascribed and claimed status, we use the term here to reflect parochial employment policies which might indicate trust, skills or other aspects of worth. 
${ }^{41}$ See Davies, "Female healers," pp.229-31 for the most recent discussion of the surgeoness. Also Arthur Wyman, "The surgeoness: The female practitioners of surgery 1400-1800," Medical History, 1984, 28, 22-41.

${ }^{42}$ Nursing in general but smallpox nursing in particular was very dangerous for the men and women involved. Fissell, Patients, Power, p.106.

${ }^{43}$ Berkshire Record Office (hereafter BRO) DP29/12/4, 'Overseers' accounts of Burghfield'. Our italics.

${ }^{44}$ Norfolk Record Office (hereafter NORO), PD431/132, Overseers' accounts.

${ }^{45}$ NRO 261P/256, Vestry book.

${ }^{46}$ BRO DP 23/18/3, Workhouse book 1772-1799.

${ }^{47}$ On other provincial examples, see Fissell, Patients, Power, pp. 61 and 66.

${ }^{48}$ BRO DP 23/18/3, Workhouse book 1772-1799.

${ }^{49}$ On this issue see Fissell, Patients, Power, p.96.

${ }^{50}$ Ibid. Borsay, "Nursing, 1700-1830", p.27, notes the ingrained assumption that poor law nursing was generally provided by other paupers.

${ }^{51}$ Well within the range suggested by Williams, "Caring", p.152.

${ }^{52}$ BRO DP7/12/1, 'Overseers' accounts of Ardington'.

${ }^{53}$ Pelling, Common Lot, p.175; Fissell, Patients, Power, p.38. Borsay and Hunter, "Nursing and Midwifery", p.21, suggest that this form of nursing care was "by far the most common".

${ }^{54}$ NRO 356p/16-24, Vestry minutes and accounts.

${ }^{55}$ Williams, "Caring”, p.153, suggests that 50 of her 77 female carers in Campton and Shefford combined could be assigned a marital status either by title or record linkage. Of these, 32\% (16) were widows while 50\% (25) were married and the remainder were spinsters, the mothers of illegitimate children or changed status. 
${ }^{56}$ BRO DP71/12/5, Overseers' accounts.

57 For instance, BRO DP91/18/11, Pauper letters. Richard Dredge, overseer of Reading, wrote to his counterpart in Pangbourne, Berkshire, in 1 September 1830 to say that Ruth Warner needed relief. He noted 'The Pauper it appears has supported herself for upwards of ten years by going out nursing. She is now upwards of seventy three years of age and I think a very proper object for to receive parochial relief'. See also Margaret Pelling, "Thoroughly resented? Older women and the medical role in early modern England", in Lynette Hunter and Sarah Hutton, eds, Women, Science and Medicine 1500-1700 (Stroud: Sutton, 1997), pp.63-87.

${ }^{58}$ NORO PD552/66, Overseers' accounts 1800-27.

${ }^{59}$ BRO DP12/7/1-2, Overseers' accounts.

${ }^{60}$ Ibid.

${ }^{61}$ BRO DP 23/18/3, Workhouse book 1772-1799.

${ }^{62}$ Williams, "Caring", p.157 suggests that in 1837 Norfolk parishes were on the higher end of the spectrum. These findings also contrast with Taylor, "Aspects", who sees rather more parsimony in his sample of Berkshire parishes.

${ }^{63}$ BRO DP26/12/3, Overseers' accounts.

${ }^{64}$ BRO DP162/12/5-12, Overseers' accounts.

${ }^{65}$ Williams, “Religion,” p.233.

${ }^{66}$ As an adjunct to this analysis it is clear that London formed its own nursing enclave in the eighteenth century, suggesting that the London-centric professionalization of nursing observed for the nineteenth century had deeper roots than we currently appreciate.

${ }^{67}$ Reflecting perhaps Fissell's observation that the poor "negotiated some small powers to themselves". Fissell, Patients, Power, p.14. 
${ }^{68}$ Steven King has also used pauper letters to investigate attitudes towards sickness and medial relief. See Steven King, "“Stop this overwhelming torment of destiny": Negotiating financial aid at times of sickness under the English Old Poor Law, 18001840," Bulletin of the History of Medicine, 2005, 79, 228-60. 